\title{
Determination of acceptable limits of adjustment of heat consumption loading
}

\author{
Sergey Glushkov ${ }^{1,}$, , Nikolay Kachalov ${ }^{1}$, Elena Senkiv ${ }^{1}$, and Victoriya Glushkova ${ }^{2}$ \\ ${ }^{1}$ National Research Tomsk Polytechnic University, 634050 Tomsk, Russia \\ ${ }^{2}$ Tomsk State Pedagogical University, 634061 Tomsk, Russia
}

\begin{abstract}
The article describes the numerical study of the temperature fields in the living quarters of an apartment building, which made it possible to evaluate the dynamics of the air temperature changes in unsteady conditions as a result of an increase or decrease in the capacity of heating appliances in relation to the standardized value. The permissible limit for adjusting the heat consumption for panel houses is determined, where the permissible period of power variation is not more than 6 hours. The range of power change in this case reaches $40 \%$. The obtained results can find its practical application in intelligent heat supply systems to minimize consumption of fuel and energy resources.
\end{abstract}

\section{Introduction}

The use of intellectual technical complexes is a promising reality, allowing at the present stage of society development to ensure the growth of its welfare. In the world practice, the tendency of using these complexes in engineering urban infrastructure was termed "smart city" [1]. It is understood as a city infrastructure of which is built on the basis of technologies allowing rational use of material, labor and energy resources and minimizes environmental impacts. It is obvious that with the implementation of the "smart city" concept, engineering infrastructure systems should have additional options compared to traditional ones. In particular, the elements of energy supply systems should be able to coordinate the production and consumption of energy according to the criterion of minimizing the consumption of fuel and energy resources by the criterion of minimization of consumption of fuel and energy resources. In this formulation, the problem of determining the acceptable limits for adjusting the loads of heat consumption is of theoretical and practical interest. It is known, that the main types of heat load in the social and domestic sphere are heating and hot water supply. The first (heating) during the heating season (for Siberia, its duration is more than $4000 \mathrm{~h}$ per year) varies from 20 to $100 \%$ of its calculated maximum and is determined mainly by the temperature of the outside air. The second load (hot water supply) on average for residential development is $20-25 \%$ of the calculated maximum of the heating load and varies within a day from 0 to $100 \%$, having two pronounced peaks on weekdays and a specific structure on Sundays and holidays, depending on the season of the year.

\footnotetext{
* Corresponding author: sglu2000@,mail.ru
} 
According to the control technology in a heating system that is not equipped with automated process control systems, heat release with a qualitative control method is carried out according to the average temperature of the previous day. In the presence of an intelligent superstructure with automated control systems of technological processes in control systems, the optimal temperature averaging period is determined by a number of factors characterizing the structure of the heat network connected to the heat source and the structure of the connected load $[2,3]$.

In this case, when planning the operation of a heat source, forecasted meteorological data is taken into account. Naturally, in these conditions, there are problems of optimizing the operation of heat sources (equalizing the daily load for boiler houses, working on electric diagrams for thermal power plants, etc.). In addition, it is important to know the limits of heat shortage in emergency situations. To solve these problems, numerical studies were carried out to determine the change in temperature fields in residential premises in case of a decrease (increase) in the consumption of heat by heating systems.

Heating devices are implemented in the model as distributed in the space heat sources, according to the location and other characteristics similar to the corresponding real heating devices.

\section{Methods of research}

The purpose of conducting numerical experiments is to determine the effect of the type of heater on the dynamics of changes in the temperature of the indoor air in a heated room due to a change in the heat input to the heating system. For a numerical experiment was taken a room located on the ground floor: height $\mathrm{H}=2.5 \mathrm{~m}$, length $\mathrm{L}=6.0 \mathrm{~m}$. The calculated area in size and shape was a vertical section along the window of the enclosing constructions and the air environment of the room. The thermophysical characteristics of the materials of the enclosing constructions and the initial conditions are identical for all calculations. The outer wall was a three-layer panel. The material of the outer and inner layers is reinforced concrete; the heat-insulating layer is made of expanded polystyrene. The material of the window frame and window sill is wood. Glass units are made of the material with equivalent thermal characteristics. The wall is reinforced concrete. In all calculations, the material of the ceilings separating the room in question from other rooms with an air temperature of $20^{\circ} \mathrm{C}$ takes into account the properties of the reinforced concrete floor with a floor covering. The peculiarity of the floor construction above the basement, in which the air temperature was $5^{\circ} \mathrm{C}$, was that on the reinforced concrete floor an additional layer of thermal insulation was fixed from below (in order to provide a normalized value of the resistance to the heat transfer of the ceiling above the basement). In the calculations, radiant heat exchange of the surfaces inside the room, window panes and the environment was taken into account.

The previous studies have shown that with diurnal fluctuations of the outdoor air temperature of $\pm 12^{\circ} \mathrm{C}$, the amplitude of fluctuations of the temperature of the indoor air in a similar room is not more than $\pm 0.4^{\circ} \mathrm{C}$ for different types of heating appliances. Therefore, in this study, the temperature of the outside air was set constant in each of the calculations.

We considered systems with three types of heating devices: 1) radiator, 2) convector, 3) floor heating. The first two types of heating devices were located under the window. In accordance with the features of the calculation algorithm, the power of the Qtot heating devices (W) was set at $1 \mathrm{~m}$ of the room width. Heat transfer from the convector and radiator consisted of radiant and convective parts [4].

Calculations were carried out for different values of the characteristic temperatures of the outside air. Each of the calculations consisted of two stages. The first is the starting calculation, which is carried out for reaching the stationary mode. For this purpose, the heat 
loads of Qtot devices were set in accordance with the heat losses of the room, calculated according to the normative method, from the condition that the internal air temperature is $20^{\circ} \mathrm{C}$. The second stage is the basic calculation performed with the changed capacity of the heater for a calculation period of 24 hours. During this calculation, the change in the average room temperature was observed.

In the case of using a radiator and a convector the similar patterns of air movement are observed. It is connected with the compactness of these appliances and similar location under the window. A completely different nature of the emerging pattern of air movement in conditions of using floor heating is caused by the distribution of heating capacity almost across the whole floor area of the room.

With an increase in the input power of up to $30 \%$ the temperature increases within $2{ }^{\circ} \mathrm{C}$ per day, its visible growth occurs in the first 12 hours, and the intensive one - in the first 6 hours. Thus, an increase in power up to $30 \%$ does not lead to significant "overheating" of premises.

We can assume that the allowable reduction in the input power is about $40 \%$, at which the temperature in the room decreases by $1.5-2.2^{\circ} \mathrm{C}$ for a period of 6 hours for the systems with radiators and convectors. For the floor heating, the period of decrease in room temperature by $2^{\circ} \mathrm{C}$ is about 24 hours. For the remaining outside air temperatures, the decrease in the room temperature over the corresponding time periods is even less [5].

Consequently, it can be considered that the acceptable regulation of the input power to the heating systems is within $40 \%$ of the calculated ambient air for a given temperature and a time period of up to 6 hours in case of compliance with the daily balance of the supplied thermal energy, taking into account fluctuations in the outside air temperature. It is crucially permissible to carry out a deeper unloading of the heating system, but in such case the variants when the duration of the cycle "decrease / increase in power" can exceed 12 hours or more are possible. Then it will be difficult to adjust the balance of the energy supplied within a day.

\section{Resume}

1. The performed numerical study of the thermal fields of living quarters as a result of the reduction (increase) in the capacity of the heating devices made it possible to determine the permissible limits of the regulation of the power of the heat supplied to the targets. The possibilities of accumulating thermal energy by residential buildings without significant fluctuations in the air temperature of the living quarters due to their warming up are limited to a time range of up to 6 hours. For the same period, it is permissible to reduce the heat power supplied to heating systems of residential buildings. The range of power variation can be up to $40 \%$.

2. The obtained results are expedient for use in automated control systems of technological processes of heat supply for the coordination of modes of generation and consumption of energy by the criterion of minimization of fuel costs.

\section{References}

1. E. Paes, Rise of the Wise: Next Steps for Smart Cities // Clinton Foundation. URL: https://www.clintonfoundation.org/blog/2013/12/09/rise-wise-next-steps-smart-cities

2. S. Glushkov, N. Kachalov, E. Senkiv, V. Glushkova, MATEC Web Conf. 92, 01072 (2017)

3. V.A. Vtyurin, Automated control systems of technological processes: teaching manual (Publishing house SPbGLA, St. Petersburg, 2006) 
4. A.I. Eremkin, T.I. Koroleva, Thermal conditions of buildings (Phoenix, Rostov-onDon, 2008)

5. D.S. Luzhkovoy, O.Yu. Romashova, A.A. Tubolev, Yu.V. Kobenko, E.S. Riabova, MATEC Web Conf. 92, 01054 (2017) 